\title{
Ginsenoside Rg3 induces apoptosis in human multiple myeloma cells via the activation of $\mathrm{Bcl}-2$-associated $\mathrm{X}$ protein
}

\author{
YUN LUO, PING ZHANG, HAN-QING ZENG, SHI-FENG LOU and DAO-XIN WANG \\ Department of Hematology, Second Affiliated Hospital of Chongqing Medical University, Chongqing 404000, P.R. China
}

Received August 4, 2014; Accepted April 16, 2015

DOI: $10.3892 / \mathrm{mmr} .2015 .3802$

\begin{abstract}
Ginsenoside $\operatorname{Rg} 3$ is one of the main constituents isolated from Panax ginseng, and exhibits cytotoxic effects against cancer cells. The present study aimed to investigate the effects of ginsenoside $\mathrm{Rg} 3$ on human multiple myeloma cells, and determine the underlying molecular mechanisms. The cells were exposed to ginsenoside $\mathrm{Rg} 3$ at various concentrations $(0-80 \mu \mathrm{M})$ for $48 \mathrm{~h}$. A subsequent cell proliferation assay demonstrated that treatment with ginsenoside $\mathrm{Rg} 3$ resulted in a dose-dependent inhibition of the proliferation of U266 and RPMI8226 cells. Furthermore, exposure to ginsenoside Rg3 led to a marked increase in the rate of apoptosis in the U266 cells, coupled with increased caspase- 3 activity. The ginsenoside $\mathrm{Rg} 3$-treated cells also exhibited an elevation in the expression of B-cell lymphoma 2-associated X protein (Bax), a pro-apoptotic protein. Notably, knockdown of Bax protected the U266 cells from Rg3-induced apoptosis. Overall, these findings suggested that ginsenoside $\mathrm{Rg} 3$ induced apoptosis in multiple myeloma cells, at least partially, through upregulation of the expression of Bax.
\end{abstract}

\section{Introduction}

Multiple myeloma is a plasma cell neoplasm, characterized by the overgrowth of mature antibody-producing plasma cells in the bone marrow. Multiple myeloma ranks as the second most common type of hematologic malignancy, following non-Hodgkin's lymphoma, with $>20,000$ new cases diagnosed annually in the USA. Despite advances in the treatment of multiple myeloma, the disease remains incurable, with a median survival rate of between 3 and 5 years (1). Patients with multiple myeloma eventually succumb to recurrent or refractory disease; therefore, there is an urgent requirement

Correspondence to: Professor Dao-Xin Wang, Department of Hematology, Second Affiliated Hospital of Chongqing Medical University, 1 Yixue Road, Chongqing 404000, P.R. China

E-mail: wwwzzz201212@163.com

Key words: B-cell lymphoma 2-associated $\mathrm{X}$ protein, natural extracts, signaling pathways, apoptosis for the identification of novel effective agents for the treatment of multiple myeloma.

Apoptosis, also termed programmed cell death, is morphologically distinct from necrotic cell death. Apoptotic cells typically exhibit chromatin condensation, the formation of apoptotic bodies and an intact cell membrane (2). There are two predominant apoptotic pathways: The extrinsic, or death receptor, pathway and the intrinsic, or mitochondrial, pathway (3). These two pathways converge on the activation of caspases, which are responsible for the execution of apoptosis through the cleavage of structural and regulatory cellular proteins and nuclear DNA. The mitochondrial pathway is primarily regulated by members of the B-cell lymphoma 2 (Bcl-2) family, which comprises pro-apoptotic proteins, including Bcl-2-associated X protein (Bax), and anti-apoptotic proteins, including Bcl-2 and Bcl-extra large (Bcl-XL) (4). Resistance to apoptosis is important in the pathogenesis of multiple myeloma, which involves the activation of multiple survival pathways, including nuclear factor $-\kappa \mathrm{B}(\mathrm{NF}-\kappa \mathrm{B})$, Janus kinase 2/signal transducers and activators of transcription (3), and phosphoinositide 3-kinase/Akt (5).

Ginseng, the root of Panax ginseng C.A. Meyer, is a herbal plant, which has received increasing attention due to its various pharmacological properties, including antitumor (6) and antioxidant properties (7). Ginsenoside $\operatorname{Rg} 3$ is one of the predominant constituents isolated from Panax ginseng, which exhibits cytotoxic effects against a wide range of cancer cells $(8,9)$. Keum et al $(10)$ reported that the antitumor activity of ginsenoside Rg3 in HL-60 human pro-myelocytic leukemia cells is partially mediated through the downregulation of $\mathrm{NF}-\kappa \mathrm{B}$. In colon (8) and prostate (9) cancer cells, ginsenoside $\mathrm{Rg} 3$ is also capable of suppressing the activation of $\mathrm{NF}-\kappa \mathrm{B}$, consequently enhancing the susceptibility of cancer cells to chemotherapeutic drugs (10). Despite evidence for the anticancer activity of ginsenoside $\mathrm{Rg} 3$, its actions in multiple myeloma remain to be fully elucidated.

The present study aimed to determine the effects of ginsenoside $\operatorname{Rg} 3$ treatment on human multiple myeloma cells, and investigate the possible underlying molecular mechanisms.

\section{Materials and methods}

Reagents. Ginsenoside $\operatorname{Rg} 3$, with a purity of $>98 \%$, was purchased from Jilin Yatai Pharmaceutical Company 
(Changchun, China). Dimethyl sulfoxide (DMSO) and 4',6-diamidino-2-phenylindole (DAPI) were purchased from Sigma-Aldrich (St.Louis, MO, USA). Fetal bovine serum (FBS) was purchased from GE Healthcare Life Sciences (Logan, UT, USA), RPMI 1640 medium was purchased from Invitrogen Life Technologies (Carlsbad, CA, USA), the Annexin V/PE Apoptosis Assay kit was obtained from Shenzhen Genmed Biological Company (Shenzhen, China) and the Caspase-3 Activity Assay kit was purchased from EMD Millipore (Billerica, MA, USA). Mouse monoclonal antibodies targeting Bax (mouse; cat no. Ab122; 1:800) and GAPDH were purchased from Beyotime Institute of Biotechnology (Shanghai, China). Horseradish peroxidase-conjugated goat anti-mouse immunoglobulin G (cat. no. ZDR-5307; 1:1,000) was obtained from Beijing Zhongshan-Golden Bridge Biological Company (Beijing, China).

Cells and culture. The U266 and RPMI8226 human multiple myeloma cells were obtained from the Cell Bank of Chinese Academy of Sciences (Shanghai, China) and cultured in RPMI 1640 medium, supplemented with $10 \%$ heat-inactivated FBS, $1 \%$ penicillin/streptomycin (Thermo Fisher Scientific, Waltham, MA, USA). The cells were maintained in a humidified incubator in $5 \% \mathrm{CO}_{2}$ and $95 \%$ air at $37^{\circ} \mathrm{C}$, and were passaged every 3-4 days.

Small interfering (si)RNA transfection. The U266 cells were seeded into six-well plates at a confluence of $40 \%$. The cells were subsequently transfected with siRNA using Lipofectamine 2000 (Invitrogen Life Technologies), according to the manufacturer's instructions.

Cell proliferation assay. The effects of ginsenoside $\operatorname{Rg} 3$ on cell proliferation were determined using an MTT assay (Beyotime Institute of Biotechnology, Shanghai, China). Briefly, the U266 cells or RPMI8226 cells were seeded into 96-well plates at a density of $1 \times 10^{4}$ cells/well $(100 \mu \mathrm{l})$ and were exposed to ginsenoside $\mathrm{Rg} 3$ at different concentrations $(20,40$ or $80 \mu \mathrm{M})$ in RPMI 1640 medium supplemented with $10 \%$ FBS. Control cells were treated with the medium only. Following treatment for $48 \mathrm{~h}$ at $37^{\circ} \mathrm{C}$, MTT solution at a final concentration of $0.5 \mathrm{mg} / \mathrm{ml}$ was added to the cells in each well. After $2 \mathrm{~h}$ incubation at $37^{\circ} \mathrm{C}, 150 \mu 1$ DMSO was added to each well, in order to dissolve the blue formazan crystals. The optical densities (OD) of the cells were measured at a wavelength of $545 \mathrm{~nm}$, with a reference wavelength of $650 \mathrm{~nm}$. The cell proliferation inhibitory rate was calculated using the following formula: Inhibitory rate $(\%)=(1-$ mean OD of experiment group / mean OD of control group) x 100 .

Analysis of apoptosis using annexin-V-fluorescein isothiocyanate (FITC)/propidium iodide (PI) with flow cytometry. The U266 cells, exposed to various concentrations of ginsenoside $\mathrm{Rg} 3$ for $48 \mathrm{~h}$, were harvested by trypsinization and washed twice with cold PBS. The cells were then centrifuged at $200 \mathrm{xg}$ for $5 \mathrm{~min}$ and the cell pellet was resuspended in $1 \mathrm{X}$ binding buffer, containing $10 \mathrm{mM}$ HEPES, $140 \mathrm{mM} \mathrm{NaCl}$ and $2.5 \mathrm{mM} \mathrm{CaCl}_{2}$, at a density of $1 \times 10^{6} \mathrm{cells} / \mathrm{ml}$. The sample solution $(100 \mu \mathrm{l})$ was transferred to a $5 \mathrm{ml}$ culture tube and incubated with FITC-conjugated annexin V and PI for
15 min at room temperature in the dark. The $1 \mathrm{X}$ binding buffer $(400 \mu \mathrm{l})$ was added to each sample tube, and the samples were analyzed on a FACScan flow cytometer (BD Biosciences, San Jose, CA, USA) using Cell Quest Research software version 3.3 (BD Biosciences).

Western blot analysis. Following treatment with ginsenoside $\operatorname{Rg} 3$, the cells were lysed in lysis buffer, containing $50 \mathrm{mmol} / 1$ tris $(\mathrm{pH} 7.4), 150 \mathrm{mmol} / 1 \mathrm{NaCl}$; $1 \%$ NP-40 and $0.1 \%$ SDS (Sangon Biotech, Inc.), supplemented with $1 \mathrm{X}$ protease and phosphatase inhibitor cocktail (Roche Diagnostics, Indianapolis, IN, USA). The protein samples were then separated on polyacrylamide gels containing $0.1 \%$ SDS and then transferred to a nitrocellulose membrane (GE Healthcare Life Sciences). The membrane was then blocked for $4 \mathrm{~h}$ at $37^{\circ} \mathrm{C}$ in tris-buffered saline (TBS) containing $5 \%$ fat-free dried milk and $0.5 \%$ Tween-20, following which the membrane was incubated with individual antibodies targeting Bax overnight at $4^{\circ} \mathrm{C}$. The membrane was then washed three times with TBS and incubated for $1 \mathrm{~h}$ with secondary antibodies at room temperature. The signals were visualized using enhanced chemiluminescence and developed on X-ray film (Carestream Health, Inc., Rochester, NY, USA). The band density was measured using the GEL DOC 2000 system equipped with Quantity One software (Bio-Rad Laboratories, Inc., Hercules, CA, USA) and normalized against the density of $\beta$-actin.

Reverse transcription quantitative polymerase chain reaction (RT-qPCR). The total RNA was extracted using TRIzol Reagent (Invitrogen Life Technologies), according to the manufacturer's instructions. The cDNA was synthesized from $1 \mu \mathrm{g}$ total RNA using an iScript ${ }^{\mathrm{TM}}$ cDNA Synthesis kit (Bio-Rad, Richmond, CA, USA). Relative gene expression levels were determined using FastStart Universal SYBR Green Master mix (Roche Diagnostics), with the mRNA expression levels of $\beta$-actin used as an endogenous control. The expression levels of the target genes were calculated using the $2^{-\Delta \Delta C \mathrm{t}}$ method.

Caspase- 3 activity assay. The activity of caspase- 3 was determined using a colorimetric assay kit. The U266 cells at $60 \%$ confluence, treated with various concentrations of ginsenoside Rg3, were washed with PBS, and lysed in caspase-3 sample lysis buffer. The cell lysates were then centrifuged at $12,000 \mathrm{x} \mathrm{g}$ for $20 \mathrm{~min}$ at $4^{\circ} \mathrm{C}$, and the resulting supernatants were assessed for protein concentration and caspase-3 activity. The protein concentration was determined using a Bicinchoninic Acid Protein Assay kit (Sigma-Aldrich). The cell lysates were incubated in reaction buffer containing a caspase-3 specific inhibitor (z-DEVD-FMK-pNA; $20 \mathrm{mmol} / \mathrm{l}$ ) for $4 \mathrm{~h}$ at $37^{\circ} \mathrm{C}$. The absorbance was measured at a wavelength of $405 \mathrm{~nm}$. Each sample was assessed in triplicate.

Statistical analysis. All data are expressed as the mean \pm standard deviation. Statistical significance was determined using Student's t-test on SPSS 19.0 software (IBM SPSS, Chicago, IL, USA). $\mathrm{P}<0.05$ was considered to indicate a statistically significant difference. 
$\mathbf{A}$

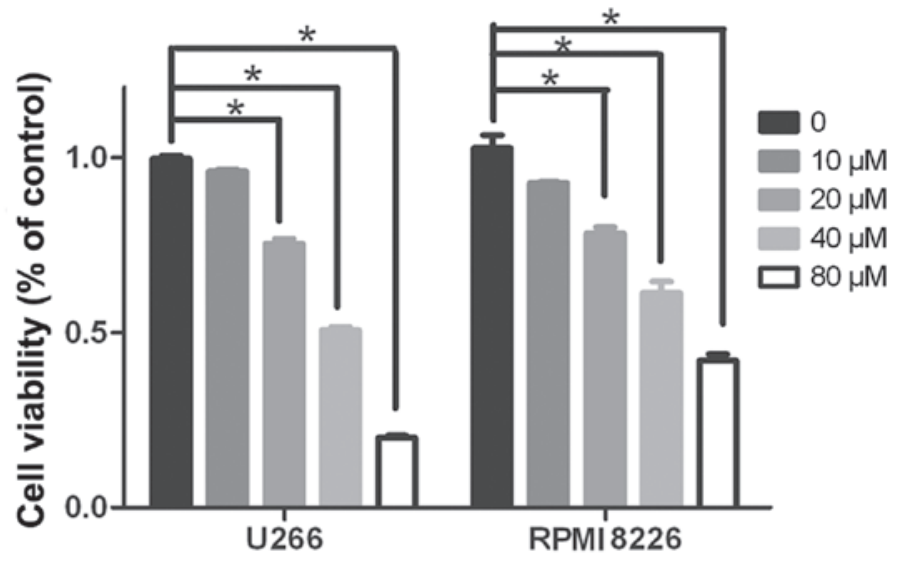

$\mathbf{B}$

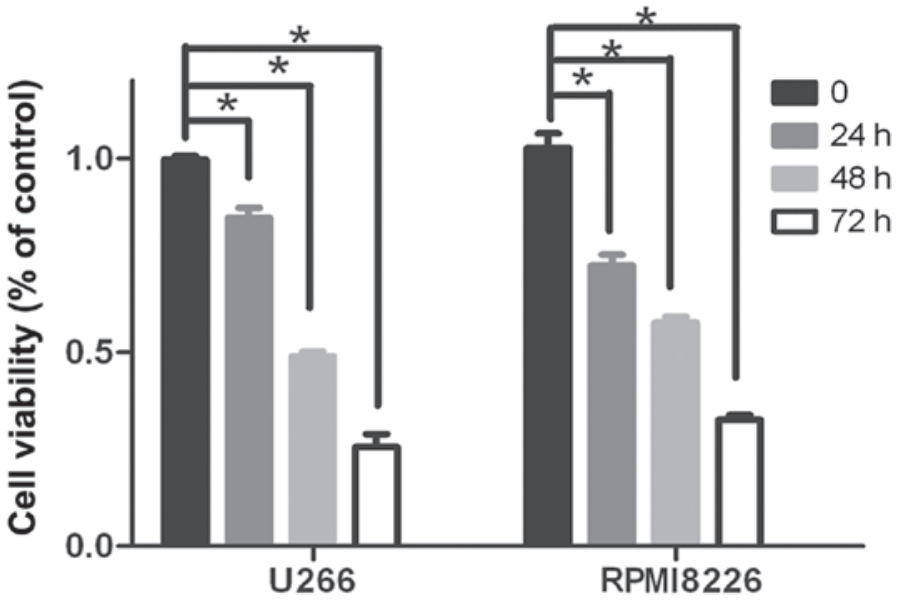

Figure 1. Treatment with ginsenoside Rg3 inhibits the proliferation of U266 and RPMI18226 human multiple myeloma cells. The cells were treated with Rg3 at (A) 10, 20, 40 or $80 \mu \mathrm{M}$ for 48 , or with (B) $40 \mu \mathrm{M} \mathrm{Rg} 3$ for $0,24,48$ or $72 \mathrm{~h}$. Cell viability was determined using an MTT assay. Data are expressed as the mean \pm standard deviation $\left({ }^{*} \mathrm{P}<0.01\right)$.

\section{Results}

Effects of ginsenoside $\mathrm{Rg} 3$ on the viability of human multiple myeloma cells. To determine whether ginsenoside Rg3 affected cancer cell growth in culture, an MTT assay was performed on U266 and RPMI8226 cells treated with increasing concentrations of $\operatorname{Rg} 3(0,10,20,40$ and $80 \mu \mathrm{M})$ for $48 \mathrm{~h}$. Treatment with ginsenoside $\mathrm{Rg} 3$ resulted in a dose-dependent inhibition of cell proliferation in the two cell lines, compared with the untreated control cells (Fig. 1A). The half maximal inhibitory concentration of ginsenoside $\mathrm{Rg} 3$ was $\sim 40 \mu \mathrm{M}$ in the $\mathrm{U} 266$ cells and $70 \mu \mathrm{M}$ in the RPMI8226 cells. The highest inhibitory rate was observed at a concentration of $80 \mu \mathrm{M}$ for $48 \mathrm{~h}$ in the two cell lines. When the cell lines were treated with $40 \mu \mathrm{M} \operatorname{Rg} 3$ for $0,24,48$ and $72 \mathrm{~h}$, the cell viability declined significantly after $24 \mathrm{~h}(\mathrm{P}<0.005$, vs. control; Fig. 1B).

Ginsenoside Rg3 induces apoptosis in U266 cells. To determine whether the antiproliferative effects of $\operatorname{Rg} 3$ were associated with the induction of apoptosis, the U266 cells were treated with 0-40 $\mu \mathrm{M} \operatorname{Rg} 3$. The rate of $\operatorname{Rg} 3$-induced apoptosis was determined in the U266 cells using annexin-V/PE staining. As shown in Fig. 2A, treatment with Rg3 at 10,20 and $40 \mu \mathrm{M}$ caused a significant increase in apoptosis, (16.2 \pm 0.46 ,
$22.1 \pm 0.83$ and $33.2 \pm 0.18 \%$, respectively) compared with the untreated control cells $(5.70 \pm 0.10 \% ; \mathrm{P}<0.05)$. Caspase -3 is universally activated during apoptotic cell death by the extrinsic (death ligand) and intrinsic (mitochondrial) pathways. To determine whether the caspase cascade mediated Rg3-induced apoptosis, caspase-3 activity was examined using pNA. The activity of caspase-3 was significantly higher in the $\operatorname{Rg} 3(60 \mu \mathrm{M})$-treated cells, compared with the untreated control cells (Fig. 2B). Furthermore, caspase-3 activity was significantly decreased when the U266 cells were pretreated with Z-DEVD-FMK, a caspase-3 inhibitor (Fig. 2C). Pre-treatment with z-DEVD-FMK attenuated the increased rate of apoptosis in the $\mathrm{Rg} 3$-treated cells, suggesting that $\mathrm{Rg} 3$ induced apoptosis in the U266 cells via the caspase-3-dependent apoptotic pathway (Fig. 2D).

Ginsenoside Rg3 enhances the expression levels of Bax. The $\mathrm{Bcl}-2$ family is important in apoptosis in leukemogenesis. To investigate the molecular mechanism underlying Rg3-induced apoptosis, the Bcl-2 family proteins were examined. The U266 cells were treated with different concentrations of ginsenoside $\operatorname{Rg} 3$. Reverse transcription-quantitative polymerase chain reaction (RT-qPCR) demonstrated that treatment with 20-80 $\mu \mathrm{M}$ ginsenoside $\mathrm{Rg} 3$ resulted in upregulated mRNA expression levels of Bax (Fig. 3A). Western blot analysis 
A
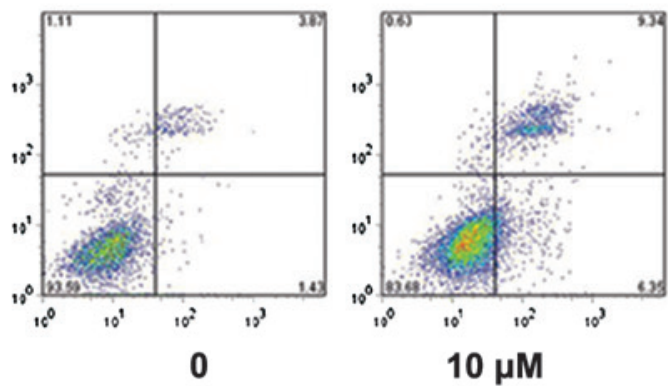

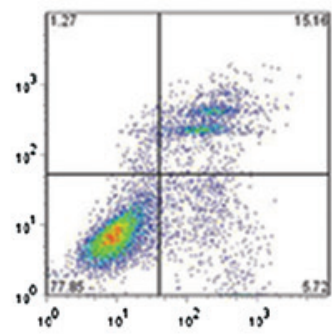

$20 \mu \mathrm{M}$

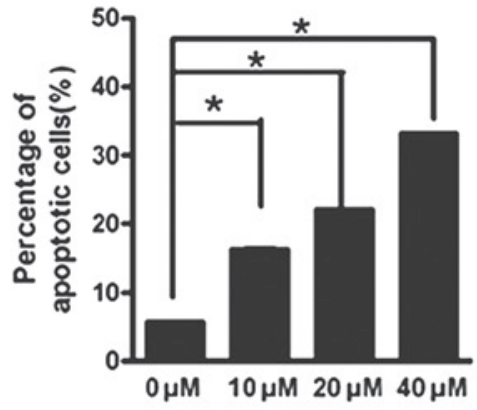

B

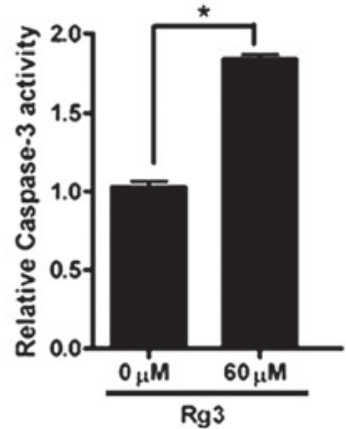

C

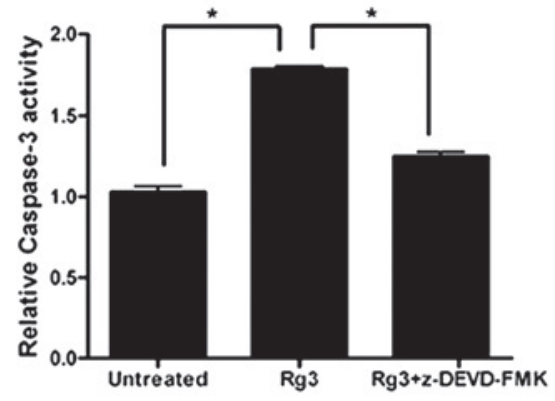

D

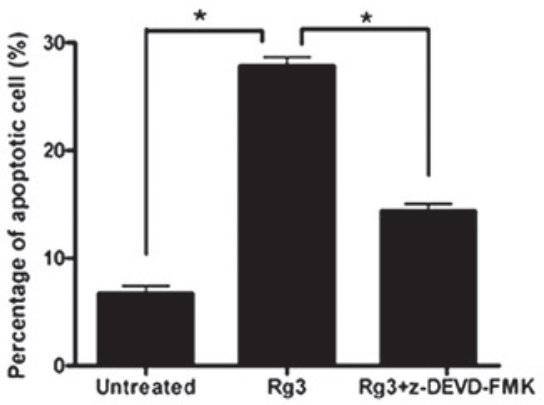

Figure 2. Treatment with ginsenoside Rg3 induces apoptosis in U266 human multiple myeloma cells. (A) Apoptosis was detected using annexin-V/phycoerythrin staining and flow cytometry. The U266 cells were treated with Rg3 at different concentrations $(0,10,20$ ot $40 \mu \mathrm{M})$ for $48 \mathrm{~h}$ prior to analysis $\left({ }^{*} \mathrm{P}<0.05\right.$, vs untreated control cells). The cells were subjected to flow cytometric analysis (left) and the bar graph demonstrates the mean percentage of apoptotic cells from three independent experiments (right). ${ }^{*}<0.05$, vs. untreated control cells. (B) Measurement of caspase-3 activity in U266 cells treated with or without ginsenoside Rg3 ("P<0.05, vs. untreated control cells). (C) Pre-treatment with z-DEVD-FMK inhibited caspase-3 activity. The U266 cells were pretreated with $20 \mathrm{mmol} / \mathrm{l}$ z-DEVD-FMK for $1 \mathrm{~h}$ prior to measuring caspase-3 activity ("P<0.05, vs. untreated control cells). (D) Effects of z-DEVD-FMK pre-treatment on Rg3-induced apoptosis. The U266 cells were pretreated with z-DEVD-FMK ( $20 \mathrm{mmol} / \mathrm{l})$ for $1 \mathrm{~h}$ and then subjected to $\mathrm{Rg} 3(40 \mu \mathrm{M})$ treatment for $48 \mathrm{~h}$. Apoptosis was detected using annexin-V/propidium iodide staining and flow cytometry. Data are expressed as the mean \pm standard deviation ( ${ }^{*} \mathrm{P}<0.01$ ),

revealed that exposure to various concentrations of ginsenoside $\operatorname{Rg} 3$ resulted in a marked reduction in the expression levels of Bax (Fig. 3B). These results suggested that treatment with ginsenoside Rg3 enhanced the expression of Bax at the transcriptional level.

Bax mediates the pro-apoptotic effects of ginsenoside $\mathrm{Rg} 3$. To determine whether Bax was essential for caspase- 3 activation, the U266 cells were transfected with small interfering
(si)RNA targeting Bax prior to Rg3 treatment. Transfection of the cells with Bax-siRNA efficiently knocked down the expression of Bax in the U266 cells (Fig. 4A). Furthermore, BAX knockdown also protected the U266 cells from $\mathrm{Rg} 3$-induced apoptosis, indicating that Rg3-induced apoptosis was partially due to upregulation of Bax (Fig. 4B). These data suggested that $\mathrm{Rg} 3$ induced apoptosis in human multiple myeloma cells, at least in part, via the Bax-dependent activation of caspase-3. 


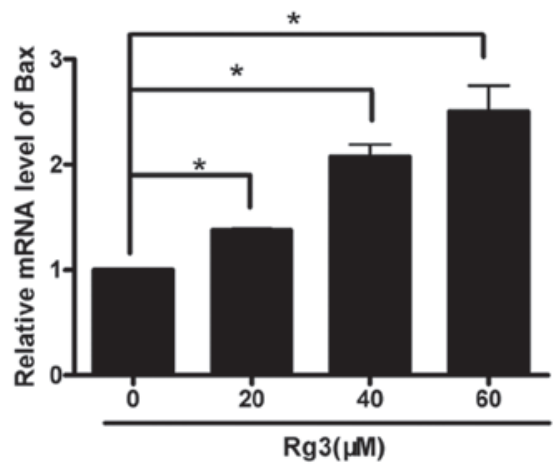

B

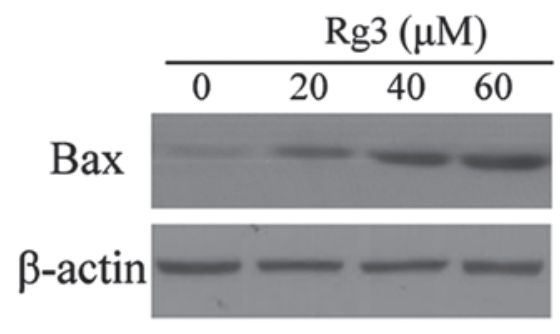

Figure 3. Treatment with ginsenoside Rg3 regulates the expression of Bax. (A) mRNA expression levels of Bax in U266 human multiple myeloma cells treated with 20-80 $\mu \mathrm{M}$ ginsenoside $\mathrm{Rg} 3$ for $48 \mathrm{~h}$. Analysis was performed using reverse transcription-quantitative polymerase chain reaction ("P<0.05). (B) Western blot analysis of the protein expression levels of Bax in Rg3-treated U266 cells. $\beta$-actin was used as a loading control. Data are expressed as the mean \pm standard deviation ( $\mathrm{P}<0.01)$. Bax, B-cell lymphoma 2-associated $\mathrm{X}$ protein.

A

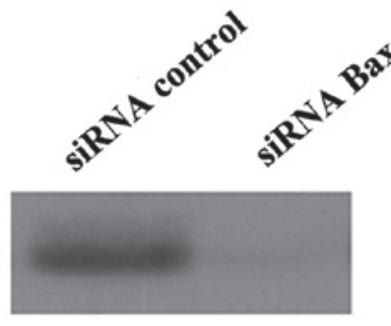

\section{$\beta$-actin}

$\mathbf{B}$
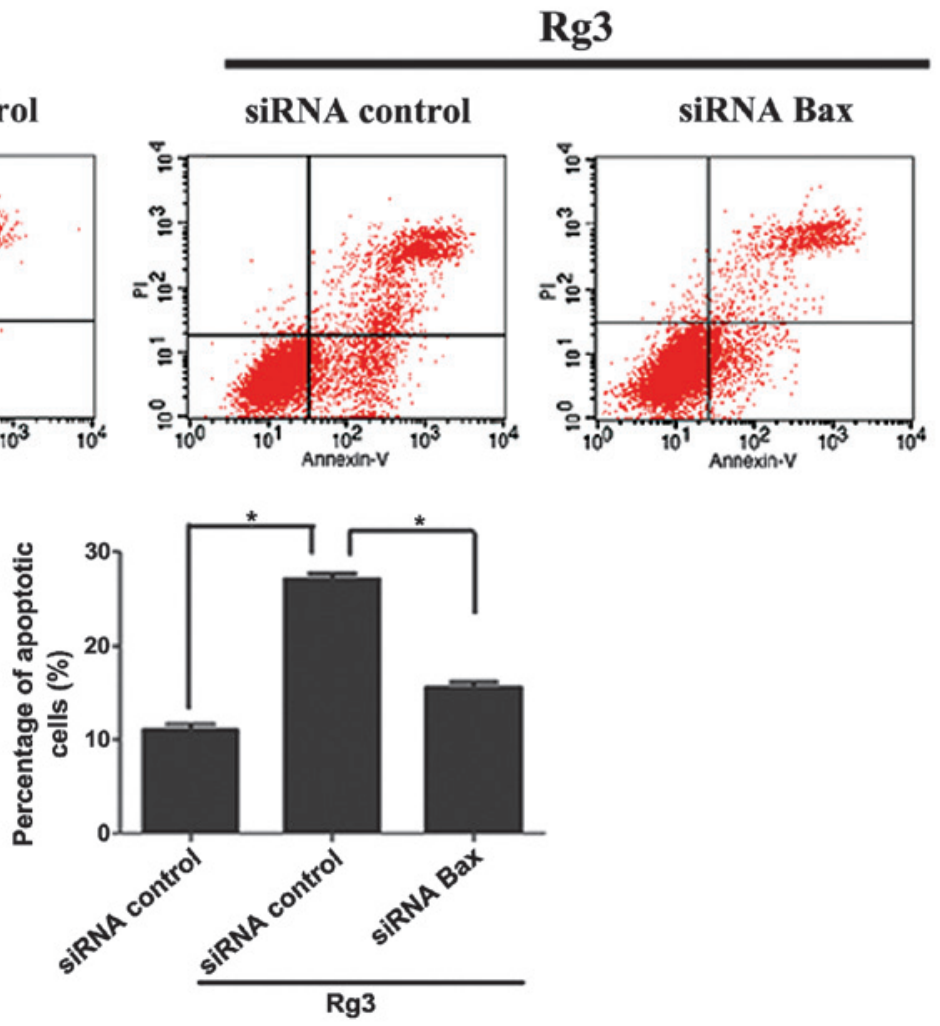

Figure 4. Bax is associated with ginsenoside Rg3-induced apoptosis. (A) Western blot analysis of the expression of Bax in U266 human multiple myeloma cells transfected with siRNA control or siRNA Bax. $\beta$-actin was used as a loading control. (B) Bax knockdown eliminated Rg3-induced apoptosis. U266 cells were transfected with siRNA or siRNA Bax and then treated with $\operatorname{Rg} 3$ (40 $\mu \mathrm{M})$ prior to flow cytometry. Bax, Bcl 2-associated X protein; siRNA, small interfering RNA; PI, propidium iodide. 


\section{Discussion}

The results of the present study demonstrated that exposure to ginsenoside $\mathrm{Rg} 3$ resulted in the dose-dependent inhibition of cell proliferation in the U266 and RPMI8226 cell lines. The anti-proliferative effect of ginsenoside $\mathrm{Rg} 3$ has been documented in other types of cancer cell, including HCC and colon cancer cells $(11,12)$. These findings indicate that ginsenoside Rg3 exhibited growth-suppressive activity in solid and hematologic malignancies. The induction of apoptosis is an important mechanism of antitumor agents. As apoptosis proceeds without disruption of plasma membrane integrity, it prevents the onset of an inflammatory response, which favors tumor progression (13). Therefore, inducing apoptosis, rather than necrosis, has been regarded as a preferred and superior strategy for clearing tumor cells. Notably, the present study demonstrated, using DAPI staining, that treatment with ginsenoside Rg3 led to apoptotic morphological changes, including nuclear condensation and fragmentation, and the formation of apoptotic bodies in the U266 cells. The results of the annexin-V/PI staining further confirmed the apoptosis-promoting role of ginsenoside $\mathrm{Rg} 3$. These results suggested that the antiproliferative activity of ginsenoside $\mathrm{Rg} 3$ in multiple myeloma cells is associated with the induction of apoptosis. Ginsenoside $\operatorname{Rg} 3$ has also been reported to suppress tumor growth by inducing tumor cell apoptosis in HCC (14).

Caspases are a family of proteases, which regulate apoptosis. The caspase family includes upstream initiator caspases, including caspase- 8 and 10, and downstream executor caspases, including caspase-3. It is widely accepted that activation of caspase-3 is essential for triggering apoptosis in several types of cell (2). Brazilin, which is isolated from Caesalpinia sappan, has been reported to promote apoptosis in U266 multiple myeloma cells through the activation of caspase-3 (15). To further investigate the possible mechanism underlying $\mathrm{Rg} 3$-induced apoptosis in human multiple myeloma, the present study examined the activity of caspase-3 in Rg3-treated cells. The data revealed that ginsenoside $\mathrm{Rg} 3$-induced apoptosis involved the activation of caspase-3 in the U266 cells, in a dose-dependent manner. In order to confirm the importance of caspase-3 for Rg3-induced apoptosis, the U266 cells were pretreated with an irreversible caspase-3 inhibitor. Rg3-induced apoptosis was decreased following the inhibition of caspase- 3 activation, suggesting that Rg3-induced apoptosis was caspase-3 dependent.

Bcl-2 family members exhibit either pro- or anti-apoptotic activities, and regulate the mitochondrial pathway of apoptosis by controlling the permeabilization of the outer mitochondrial membrane (16). Activated Bax is involved in the formation of pores in the outer mitochondrial membrane, which allow the release of cytochrome $c$ from the mitochondria, consequently leading to activation of caspases (16). The present study demonstrated that exposure to ginsenoside $\mathrm{Rg} 3$ resulted in a marked enhancement of the mRNA and protein expression levels of Bax. Notably, silencing the expression of Bax reduced the activation of caspase- 3 and the levels of apoptosis in the Rg3-treated U266 cells. These findings collectively suggested that ginsenoside $\operatorname{Rg} 3$ induced apoptosis in human multiple myeloma cells by modulating the expression of Bax, which triggered the caspase-3-dependent pathway. Activation of the mitochondrial pathway of apoptosis by ginsenoside Rg3 has also been documented in HCC (14-17) and colon cancer cells (12).

In conclusion, the present study demonstrated that ginsenoside $\operatorname{Rg} 3$ inhibited the proliferation and induced the apoptosis of human multiple myeloma cells. Furthermore, Rg3-induced apoptosis was partially due to upregulation of Bax. However, there were certain limitations to the present study. The detailed signaling pathways involved in ginsenoside $\mathrm{Rg} 3$-induced apoptosis in multiple myeloma cells require further elucidation. In addition, whether these findings can be translated into the clinical setting remains to be elucidated. Therefore, further investigation is required to assess the possible therapeutic application of ginsenoside $\operatorname{Rg} 3$ in human multiple myeloma therapy.

\section{References}

1. Mahindra A, Laubach J, Raje N, Munshi N, Richardson PG and Anderson K: Latest advances and current challenges in the treatment of multiple myeloma. Nat Rev Clin Oncol 9: 135-143, 2012.

2. Ouyang L, Shi Z, Zhao S, Wang FT, Zhou TT, Liu B and Bao JK: Programmed cell death pathways in cancer: A review of apoptosis, autophagy and programmed necrosis. Cell Prolif 45: 487-498, 2012.

3. Danial NN and Korsmeyer SJ: Cell death: Critical control points. Cell 116: 205-219, 2004.

4. Kale J, Liu Q, Leber B and Andrews DW: Shedding light on apoptosis at subcellular membranes. Cell 151: 1179-1184, 2012.

5. Oancea M, Mani A, Hussein MA and Almasan A: Apoptosis of multiple myeloma. Int J Hematol 80: 224-231, 2004.

6. Kang KA, Kim HS, Kim DH and Hyun JW: The role of a ginseng saponin metabolite as a DNA methyltransferase inhibitor in colorectal cancer cells. Int J Oncol 43: 228-236, 2013.

7. Ma SW, Benzie IF, Chu TT, Fok BS, Tomlinson B and Critchley LA: Effect of Panax ginseng supplementation on biomarkers of glucose tolerance, antioxidant status and oxidative stress in type 2 diabetic subjects: Results of a placebo-controlled human intervention trial. Diabetes Obes Metab 10: 1125-1127, 2008.

8. Kim SM, Lee SY, Yuk DY, Moon DC, Choi SS, Kim Y, Han SB, Oh KW and Hong JT: Inhibition of NF-kappaB by ginsenoside $\mathrm{Rg} 3$ enhances the susceptibility of colon cancer cells to docetaxel. Arch Pharm Res 32: 755-765, 2009.

9. Kim SM, Lee SY, Cho JS, Son SM, Choi SS, Yun YP, Yoo HS, Yoon do Y, Oh KW, Han SB and Hong JT: Combination of ginsenoside $\mathrm{Rg} 3$ with docetaxel enhances the susceptibility of prostate cancer cells via inhibition of NF-kappaB. Eur J Pharmacol 63: 1-9, 2010.

10. Keum YS, Han SS, Chun KS, Park KK, Park JH, Lee SK and Surh YJ: Inhibitory effects of the ginsenoside Rg3 on phorbol ester-induced cyclooxygenase-2 expression, NF-kappaB activation and tumor promotion. Mutat Res 523-524: 75-85, 2003.

11. Yu Y, Zhang C, Liu L and Li X: Hepatic arterial administration of ginsenoside $\operatorname{Rg} 3$ and transcatheter arterial embolization for the treatment of VX2 liver carcinomas. Exp Ther Med 5: 761-766, 2013.

12. Yuan HD, Quan HY, Zhang Y, Kim SH and Chung SH: 20(S)-Ginsenoside Rg3-induced apoptosis in HT-29 colon cancer cells is associated with AMPK signaling pathway. Mol Med Rep 3: 825-831, 2010.

13. Sethi G, Shanmugam MK, Ramachandran L, Kumar AP and Tergaonkar V: Multifaceted link between cancer and inflammation. Biosci Rep 32: 1-15, 2012.

14. Jiang JW, Chen XM, Chen XH and Zheng SS: Ginsenoside Rg3 inhibit hepatocellular carcinoma growth via intrinsic apoptotic pathway. World J Gastroenterol 17: 3605-3613, 2011.

15. Kim B, Kim SH, Jeong SJ, Sohn EJ, Jung JH, Lee MH and Kim SH: Brazilin induces apoptosis and G2/M arrest via inactivation of histone deacetylase in multiple myeloma U266 cells. J Agric Food Chem 60: 9882-9889, 2012.

16. Brunelle JK and Letai A: Control of mitochondrial apoptosis by the Bcl-2 family. J Cell Sci 122: 437-441, 2009.

17. Park HM, Kim SJ, Kim JS and Kang HS: Reactive oxygen species mediated ginsenoside $\mathrm{Rg} 3$ - and $\mathrm{Rh} 2$-induced apoptosis in hepatoma cells through mitochondrial signaling pathways. Food Chem Toxicol 50: 2736-2741, 2012. 